\title{
Day Traders, Computers and the Trading Floor - Interactional Expertise?
}

\author{
Claire McAndrew \\ London College of Communication \\ University of the Arts London, UK \\ c.mcandrew@lcc.arts.ac.uk
}

\author{
Julie Gore \\ Faculty of Management \& Law \\ University of Surrey, UK \\ j.gore@surrey.ac.uk
}

\begin{abstract}
Motivation - Despite the intersection between naturalistic decision making (NDM) and the environments in which day traders operate, little research has applied NDM theory and methods to the study of day trading practices. Research approach - In-depth interviews using applied cognitive task analysis (ACTA) were conducted with eight UK-based day traders. Findings - Nine cognitively complex elements of expertise were identified, highlighting the inextricable link between day traders' cognition, the trading floor in which they operate and computer technology with which they interact. Research limitations/Implications - Despite limitations associated with the generalisability of findings, it is hoped the research will demonstrate the utility of applying qualitative methods such as ACTA to the field of behavioural finance. Originality/Value - This work is original in its application of a 'naturalistic' mode of enquiry and macrocognitive theory to what has been coined a microcognitive domain. Take away message - 'Interactional expertise' is a useful concept for understanding day traders' decision-making.
\end{abstract}

Keywords

Day trading, applied cognitive task analysis, interactional expertise

\section{INTRODUCTION}

This research was initiated by the recognition of the similarities that exist between Orasanu and Connolly's (1993) characteristics of naturalistic decision making (NDM) and those exhibited by day traders' activities and the information environments in which they operate (McAndrew, 2008). Despite this intersection, little research has applied NDM theory and methods to this domain. Research from a psychological perspective has tended to explore probabilistic forecasting (Staël von Holstein, 1972), the relationship between personality profiling and risk propensity (FentonO'Creevy, Nicholson, Sloane \& Willman, 2005) and the use of heuristics and biases under conditions of uncertainty (Borges, Goldstein, Ortmann \& Gigerenzer, 1999). Whilst Mieg's (2001) discussion of whether there can be expertise in the forecasting of financial markets highlighted the appropriateness of applying social psychological and cognitive theory to this domain - the utility of drawing upon NDM theorem has not been fully realised. The research documented in this paper seeks to rectify this anomaly applying NDM to the examination of day trading practices. Our interest stems from the realisation that day traders' interaction with computing technology is an essential feature, to the extent that there is an "intricate recursivity and interdependence of participants (and their actions)" (Mieg, 2001: 122). That is, technical analysis of market data and inferences based on the underlying psychology of the market inform traders' decisions (i.e. price-action), which then feed back into the market shaping future actions and so ad infinitum. By applying NDM methodology, it was anticipated that the nature of this complex interaction might be better understood in macrocognitive terms, with particular attention focusing upon how day traders manage uncertainty and make sense of dynamically changing markets as a basis of action.

\section{METHOD}

In-depth interviews using applied cognitive task analysis (ACTA) (Militello \& Hutton, 1998) were conducted with eight day traders drawn from four UK trading firms. All participating firms had divisions that traded with a proprietary and discretionary element (trading for a direct profit from the market rather than earning commission from processing trades). The interviews used stage one: task diagram and stage two: knowledge audit of the ACTA techniques, which were then merged into a cognitive demands table.

\section{FINDINGS}

The completion of a cognitive demands table identified nine cognitively complex elements underpinning day traders' expertise: (i) identifying emerging trends, (ii) responding to trend reversals, (iii) detecting regime shifts, (iv) taking action following sudden interruption to supply, (v) exploiting price anomalies, (vi) anticipating effect of change in market fundamentals, (vii) using inter-relationships between alternative markets to inform market view, (viii) amending trading strategy in lieu of shifting market conditions and (ix) trying not to sub-optimise opportunities. For each of these, the ACTA techniques were useful in highlighting the inextricable link between day traders' cognition, the trading floor in which they operate and the computer technology with which they interact. For example, the task of identifying an 
emerging trend and associated 'buy' opportunities was shown to be dependent upon both computer-assisted technical analysis and inferences regarding other market players' actions. The ACTA techniques were also useful in highlighting the web of macrocognitive processes that enable day traders to manage uncertainty and make sense of dynamically changing markets. For example, the management of uncertainty when trying not to sub-optimise given opportunities can be achieved by trading contracts with optionality, trading in lags and/or by marrying own and client positions. Sense-making processes were also shown to be integral when identifying emerging trends (i.e. bull markets and rallies). These included for instance, the use of technical analysis in conjunction with past experience to identify channels of higher highs / lows as indicative of a trend in market, Fibonnaci retracements ${ }^{1}$ as leverage points for action and mental simulation to anticipate market corrections. As such, this study advocates the notion of interactional expertise (i.e. one that occurs between task, technology and environment) in understanding day traders' cognition and demonstrates the value of a macrocognitive framework for the interpretation of their expertise.

This research has added to contemporary debate by demonstrating how qualitative methods such as ACTA can be applied to the domain of day trading in order to provide a task-focused study of expertise (see also Gore \& McAndrew, 2009). The ACTA techniques were considered a useful tool for quickly understanding the major cognitive challenges within this time-critical domain and thereby demonstrate the utility in studying day traders' decision-making from a NDM perspective. However, despite the amount of data generated, consolidation into both the knowledge audit and the cognitive demands tables resulted in the loss of information. Developments in recording data are therefore required.

\section{IMPLICATIONS}

There are three key implications of this study: First, it demonstrates the utility of applying qualitative methods such as ACTA to the domain of behavioural finance. Second, (and in building upon this contribution), this study demonstrates the utility of understanding decision-making as an interactional expertise. Finally, this research demonstrates the value of interpreting day traders' decision activities within a macrocognitive framework.

\section{CONCLUSIONS}

This study has made a topical contribution by demonstrating the value of applying a 'naturalistic' mode of enquiry to the study of day traders. It has also been useful in providing insights into the recursivity and interdependence of day traders' actions, computers and the trading floor and illustrated the usefulness of macrocognition as a concept to better understand this phenomenon. The key conclusion follows that interactional expertise is an appropriate concept for understanding day traders' decision-making and that value can be drawn from applying macrocognitive theory to a domain that has traditionally been approached from a microcognitive perspective (McAndrew, Banks \& Gore, 2008).

\section{ACKNOWLEDGMENTS}

We would like to thank the Faculty of Management \& Law at the University of Surrey, for funding the doctoral work upon which this research is based. We would also like to express our gratitude to those participants who were generous enough to invest their time and share their expertise.

\section{REFERENCES}

Borges, B., Goldstein, D. G., Ortmann, A. \& Gigerenzer, G. (1999). Can ignorance beat the stock market? In G. Gigerenzer, P.M. Todd \& the ABC Research Group (Eds.), Simple heuristics that make us smart (pp. 59-72). Oxford University Press, New York.

Fenton-O’Creevy, M., Nicholson, N., Sloane, E. \& Willman, P. (2005). Traders: Risks, decisions and management in financial markets, Oxford University Press, Oxford.

Gore, J. \& McAndrew, C. (2009). Accessing expert cognition, The Psychologist, 22, 3, 218-219.

McAndrew, C. (2008). Cross-fertilising methods in naturalistic decision making and managerial cognition, Unpublished PhD Thesis, University of Surrey, UK.

McAndrew, C., Banks, A. \& Gore, J. (2008). Bridging macrocognitive / microcognitive methods: ACT-R under review. In M. Schraagen, L. Militello, T. Ormerod \& R. Lipshitz (Eds.), Naturalistic decision making and macrocognition (pp. 277-299). Ashgate, Aldershot.

Mieg, H.A. (2001). Experts - risk - financial markets. In H.A. Mieg (Ed.), The social psychology of expertise: Case studies in research, professional domains and expert roles (pp. 92-122). Lawrence Erlbaum, Mahwah, NJ.

Militello, L.G. \& Hutton, R.J.B. (1998). Applied cognitive task analysis (ACTA): A practitioner's toolkit for understanding cognitive task demands, Ergonomics, 41, 11, 1618-1641.

Orasanu, J. \& Connolly, T. (1993). The reinvention of decision-making. In: G.A. Klein, J. Orasanu, R. Calderwood \& C.E. Zsambok (Eds.), Decision making in Action: Models and methods (pp. 3-20). Ablex, Norwood, NJ.

Staël von Holstein, C.A.S. (1972). Probability encoding in decision analysis, Journal of Forecasting, 5, 171-178.

${ }^{1}$ In technical analysis, a Fibonacci retracement is created by taking a major peak and trough on a chart and dividing the vertical distance by the key Fibonacci ratios of $23.6 \%, 38.2 \%, 50 \%, 61.8 \%$ and $100 \%$. Once these levels are identified, horizontal lines are drawn and used to identify potential support and resistance levels. These can be used to determine critical points that cause a market to reverse. The direction of the prior trend is likely to continue once the market has retraced to one of the ratios listed above. 